\title{
Mechanical Properties of High-Viscosity Glass Ionomer Cement and Nanoparticle Glass Carbomer
}

\author{
Isabel Cristina Olegário, ${ }^{1}$ Anna Paula Vieira Ferreira Prado Malagrana, \\ Sabrina Sun Ha Kim, ${ }^{2}$ Daniela Hesse, ${ }^{1}$ Tamara Kerber Tedesco, ${ }^{1}$ \\ Ana Flávia Bissoto Calvo, ${ }^{1}$ Lucila Basto Camargo, ${ }^{1}$ and Daniela Prócida Raggio ${ }^{1}$ \\ ${ }^{1}$ Department of Pediatric Dentistry, School of Dentistry, University of São Paulo (USP), Avenida Professor Lineu Prestes 2227, \\ 05508-000 São Paulo, SP, Brazil \\ ${ }^{2}$ School of Dentistry, University of São Paulo (USP), Avenida Professor Lineu Prestes 2227, 05508-000 São Paulo, SP, Brazil \\ Correspondence should be addressed to Daniela Prócida Raggio; danielar@usp.br
}

Received 15 December 2014; Accepted 27 January 2015

Academic Editor: Victor M. Castaño

Copyright (C) 2015 Isabel Cristina Olegário et al. This is an open access article distributed under the Creative Commons Attribution License, which permits unrestricted use, distribution, and reproduction in any medium, provided the original work is properly cited.

Introduction. The lack of evidence regarding the best available material for restoring occlusal-proximal cavities in primary teeth leads to the development of new restorative material, with nanoparticles, in order to enhance mechanical properties, resulting in increased restoration longevity. Aim. To evaluate the Knoop hardness and bond strength of nanoparticles material glass carbomer cement (CAR) and high-viscosity glass ionomer cement (GIC) in sound and caries-affected dentin. Methods. Forty bovine incisors were selected and assigned into four groups $(n=10)$ : SGIC, sound dentin and GIC; SCAR, sound dentin and CAR; CGIC, caries-affected dentin and GIC; and CCAR, caries-affected dentin and CAR. All groups were submitted to microshear bond strength (MPa). Knoop hardness was also performed. Bond strength values were subjected to two-way ANOVA and Tukey test. Knoop hardness data were subjected to one-way ANOVA. Results. GIC presented higher Knoop hardness $(P<0.001)$ and bond strength $(P=0.027)$ than CAR. Also, both materials showed better performance in sound than in caries-affected substrates $(P=0.001)$. The interaction between factors was not statistically different $(P=0.494)$. Conclusion. Despite nanoparticles, CAR shows inferior performance as compared to GIC for the two properties tested in vitro. Moreover, sound dentin results in better bonding performance of both restorative materials evaluated.

\section{Introduction}

The current state of cariology advocates concepts of minimal intervention (MI) for the management of caries lesions [1] and tied to this concept is the atraumatic restorative treatment (ART). The ART restores cavities, requiring no electricity or conventional dental chair [2] and preserving dental structure. Moreover, educational and preventive measures, such as sealants, manage the caries disease.

The material of choice for ART restoration is the highviscosity glass ionomer cement (GIC), due to its biocompatibility, facility of use, antimicrobial effect, and chemical bonding to tooth structures, resulting in an efficient marginal sealing [3]. Also, this material releases and uptakes fluoride, benefiting the remineralization of restored tooth $[4,5]$ and also the surfaces adjacent to restorations [6].

The GIC bonding to the tooth structure is based on two principles. The first one is the principle of hybridization $[7,8]$. The GIC polyacrylic acid promotes the exposure of collagens fibers and the ionomeric components of GIC diffuse through this collagen matrix, thus establishing micromechanical retention. The second principle (and the most important) is based on an ionic interaction between the carboxyl groups of the polyacrylic acid and the calcium ions of the hydroxyapatite that remains bonded to the tooth collagen fibers.

Along with the advantages of GIC, there are some drawbacks that impair its use, such as low fracture strength, surface wear [9-11], and slow setting reaction that may postpone or 
even compromise its final strength [12]. In an attempt to overcome those shortcomings, high energy light was employed to fasten the set reaction of GIC, resulting in improved adhesion of GIC to the enamel as well as a decreased wear of the material $[13,14]$. Another interesting event related to the changes in GIC composition over time with the formation of "enamellike structures" [15] led to the development of glass-ionomerbased filling material called glass carbomer cement (CAR). CAR contains nanosized powder particles and fluorapatite as secondary filler and has been introduced with claims of improved physical characteristics in comparison with GIC. The manufacturer declares that the incorporation of nanosized filler particles into the CAR combined with the light-curing sources with a high output range results in an improved compressive strength and wear resistance [16].

Since there is limited published data on the clinical performance of CAR [17-20], laboratory tests may contribute with valuable insights into the physical-mechanical properties of this material. Therefore, the aim of this study was to evaluate the Knoop hardness and microshear bond strength of CAR and a high-viscosity GIC to sound and caries-affected dentin.

\section{Materials and Methods}

\subsection{Microshear Bond Strength Test}

2.1.1. Sample Selection and Preparation. Forty bovine incisors were selected according to inclusion criteria of absence of cracks or opacities. These characteristics were evaluated by visual examination. Teeth were then randomly assigned into four experimental groups $(n=10)$ : SGIC, sound dentin and GIC Fuji IX (GC Corp., Leuven, Belgium); SCAR, sound dentin and glass carbomer (GCP Dental, Vianen, The Netherlands); CGIC, caries-affected dentin and GIC Fuji IX; and CCAR, caries-affected dentin and glass carbomer.

The root portion of teeth was removed by cutting along transversal plane using a cutting machine (Labcut 1010; Erios, Technical and Scientific Equipment Ltd., São Paulo, Brazil) at $3 \mathrm{~mm}$ of the enamel-cement junction with a diamond disk. The buccal surfaces of teeth were ground with rotary polisher with 180-grit SiC paper, always under water cooling, to obtain a flat dentin surface. For standardization of the smear layer, the dentin surfaces were then ground for $60 \mathrm{~s}$ with 600-grit $\mathrm{SiC}$ paper. The obtained dentin surfaces were examined in stereomicroscope (Olympus SZ61, Tokyo, NRT, Japan) with 20x magnification to ensure the absence of the enamel and the exposure of pulp horns, respectively.

2.1.2. Cariogenic Challenge. Teeth of the GIC and CAR groups were submitted to cariogenic challenge by $\mathrm{pH}$-cycling for the development of caries-affected dentin [21]. The specimens were covered with two layers of acid-resistant nail polish, with the exception of the exposed buccal dentin surfaces. Teeth were then immersed in $10 \mathrm{~mL}$ of demineralizing solution $\left(2.2 \mathrm{mM} \mathrm{CaCl}_{2}, 2.2 \mathrm{mM} \mathrm{NaH} \mathrm{PO}_{4}\right.$, and $50 \mathrm{mM}$ acetic acid, adjusted to $\mathrm{pH} 4.8$ ) and in the same volume of remineralizing solution $\left(1.5 \mathrm{mM} \mathrm{CaCl}_{2}, 0.9 \mathrm{mM} \mathrm{NaH}_{2} \mathrm{PO}_{4}\right.$, and $0.15 \mathrm{M} \mathrm{KCl}$ adjusted to $\mathrm{pH} 7.0$ ). Each specimen was cycled for 8 hours in demineralizing solution and 16 hours in remineralizing solution. These procedures were repeated for 14 days at room temperature and without agitation.

\subsubsection{Bonding Procedure and Microshear Bond Strength Test.} The pretreatment of dentin sections was initially performed according to manufacturer's instructions. Polyethylene tubes (Microbore Tygon S-54-HL Medical Tubing Saint-Gobain Performance Plastics, Akron, USA) with $1.0 \mathrm{~mm}$ high and $1.13 \mathrm{~mm}$ inside diameter were placed on the pretreated surfaces of exposed dentin and filled with one of restorative materials, covered with a matrix strip, and gently pressed with a glass slide, according to experimental groups.

The specimens were stored in distilled water at $37^{\circ} \mathrm{C}$ for 24 hours. After this period, the polyethylene tubes were removed and the specimens were examined under microscope with $10 \mathrm{x}$ magnification. If there were interfacial gaps, bubble inclusion, or other defects in the interface, they were eliminated from the test. The specimens were then fixed to the device to be submitted immediately to microshear test in a universal testing machine (Kratos, Kratos dynamometers, Embu, Brazil) with a speed of $0.5 \mathrm{~mm} / \mathrm{min}$ until failure occurred.

2.2. Knoop Hardness. To analyze the Knoop hardness of the evaluated restorative materials, five cylindrical specimens of each restorative material with $11 \mathrm{~mm}$ diameter and $1.5 \mathrm{~mm}$ height were prepared in a stainless steel mold. Both restorative materials were mixed according to manufactures instruction, applied into a mold with a syringe (Centrix, DFL, Rio de Janeiro, Brazil), leaving a slight excess. A matrix strip of polyester matrix was placed covering the specimen surface and gently pressed with a glass slide for 1 minute. Specimens remained within the matrix for 20 minutes and after this period they were removed and received a thin layer of petroleum jelly for surface protection.

Specimens were taken to microhardness test $(25 \mathrm{~g} / 5 \mathrm{sec}$ dwell time); then, measurements of the major axis of the diamond marked by the tip of the indenter were made. The values were expressed in Knoop hardness. In each specimen, five indentations were performed, and the average of all measures was used for statistical purposes.

2.3. Statistical Analysis. The homogeneity of variances was confirmed using Levene's test $(P=0.052)$. The bond strength values $(\mathrm{MPa})$ were subjected to two-way analysis of variance (substrate and restorative material) and Tukey post hoc test. Likewise, the Knoop hardness data were subjected to one-way ANOVA (restorative material). All analyzes were performed with a significance level set at $5 \%$.

\section{Results}

3.1. Microshear Bond Strength Test. Table 1 displays the means and standard deviation of all experimental groups of the microshear bond strength test. Analysis of variance showed a significant difference only for the main factors "substrate" $(P<0.001)$ and "restorative material" $(P=0.027)$ (Table 1$)$. 
TABLE 1: Microshear bond strength means (standard deviation) of all experimental groups.

\begin{tabular}{lcc}
\hline $\begin{array}{l}\text { Restorative } \\
\text { material }\end{array}$ & Sound dentin & $\begin{array}{c}\text { Caries-affected } \\
\text { dentin }\end{array}$ \\
\hline $\begin{array}{l}\text { Glass ionomer } \\
\text { cement }\end{array}$ & $1.74(0.40)^{\mathrm{a}, \mathrm{C}}$ & $1.11(0.26)^{\mathrm{b}, \mathrm{C}}$ \\
Glass carbomer & $1.34(0.63)^{\mathrm{a}, \mathrm{D}}$ & $0.89(0.28)^{\mathrm{b}, \mathrm{D}}$ \\
\hline
\end{tabular}

*Different lowercase letters indicate statistical difference between rows (restorative material).

** Different uppercase letters indicate statistical difference between the columns (substrate).

TABLE 2: Knoop hardness means and standard deviation of the restorative materials.

\begin{tabular}{lc}
\hline Restorative material & Knoop hardness \\
\hline Glass ionomer cement & $24.32(1.21)^{\mathrm{a}}$ \\
Glass carbomer & $20.80(1.61)^{\mathrm{b}}$ \\
\hline
\end{tabular}

${ }^{*}$ Different lowercase letters indicate statistical difference between the restorative materials.

The interaction between factors was not statistically different $(P=0.494)$. GIC had higher bond strength (BS) than CAR, regardless of the substrate. Furthermore, sound dentin resulted in better performance than caries-affected dentin for both materials.

3.2. Knoop Hardness. Knoop hardness means of both restorative materials are displayed in Table 2. Analysis of variance revealed a statistically significant difference between the materials $(P<0.001)$, whereas the GIC showed higher Knoop hardness than CAR (Table 2).

\section{Discussion}

As ART has become quite well settled in the literature for occlusal cavities in primary and permanent teeth, the main focus of contemporary research is the occlusal-proximal surfaces [22].

The lack of evidence for the best available restorative material for dental treatments in primary teeth [23] leads to the development of new restorative materials, such as CAR. Although the literature shows that it has nanosized powder particles and fluorapatite as a secondary payload, which is claimed to improve the compressive strength and resistance [24], this is the first study that compared the bond strength and hardness of CAR with GIC, and the results showed that the high-viscosity GIC resulted in higher bond strength and Knoop hardness than the CAR.

It could be explained by the chemical reaction of hydroxyapatite (HAp) during the solidification process, as reported in the study conducted by Zainuddin et al., 2012 [25], which showed that HAp was partially consumed during this stage. Thus, we hypothesized that the consumed apatite in CAR could be associated with the carboxylic groups' interactions, decreasing the available ions to bond with mineral content of teeth, resulting in lower bond strength.
A previous study found that CAR has higher microleakage when compared to GIC, showing the presence of internal and surface cracks [24]. The authors speculate that dehydration possibly occurs after using the light unit to activate the material, a factor that may result in deterioration of the surface and also of the interface between dentin and material [24]. This material deterioration induced by light can be a possible explanation for worse bonding performance of this material to dentin compared to GIC observed in the present study.

Better bonding of both restorative materials in sound dentin when compared to caries-affected dentin was also observed, corroborating with previous studies that have shown similar trend when evaluating GIC [26]. One possible explanation is related to the higher amount of exposed collagen and the lower hydroxyapatite crystals in cariesaffected dentin, which are important factors for bonding of the restorative material [27]. In addition, the higher porosity observed in caries-affected dentin could result in improper infiltration of the restorative material, leading to lower levels of bond strength between dentin and restorative materials [28].

However, this is the first in vitro study that compared these materials to be used as ART restorative filling. Thus, further clinical trials might be designed and conducted to confirm the better performance of GIC in the clinical setting. Our group has designed and started one randomized clinical trial for primary teeth with these restorative materials (Clinical Trials NCT02217098), and the evaluations are being performed. Soon we will have clinical data to compare with those laboratorial results.

\section{Conclusion}

The evaluated high-viscosity glass ionomer cement results in higher Knoop hardness and microshear bond strength when compared to glass carbomer. Moreover, both materials show better bond strength in sound dentin than in caries-affected dentin.

\section{Conflict of Interests}

The authors declare that there is no conflict of interests regarding the publication of this paper.

\section{Acknowledgments}

The authors would like to thank FAPESP, CAPES, and CNPq for financial support.

\section{References}

[1] C. A. Murdoch-Kinch and M. E. McLean, "Minimally invasive dentistry," Journal of the American Dental Association, vol. 134, no. 1, pp. 87-95, 2003.

[2] J. E. Frencken, M. A. van 't Hof, W. E. van Amerongen, and C. J. Holmgren, "Effectiveness of single-surface ART restorations in the permanent dentition: a meta-analysis," Journal of Dental Research, vol. 83, no. 2, pp. 120-123, 2004. 
[3] A. D. Wilson and B. E. Kent, "A new translucent cement for dentistry. The glass ionomer cement," British Dental Journal, vol. 132, no. 4, pp. 133-135, 1972.

[4] S. Mickenautsch, V. Yengopal, S. C. Leal, L. B. Oliveira, A. C. Bezerra, and M. Bönecker, "Absence of carious lesions at margins of glass-ionomer and amalgam restorations: a metaanalysis," European Journal of Paediatric Dentistry, vol. 10, no. 1, pp. 41-46, 2009.

[5] A. Wiegand, W. Buchalla, and T. Attin, "Review on fluoridereleasing restorative materials-fluoride release and uptake characteristics, antibacterial activity and influence on caries formation," Dental Materials, vol. 23, no. 3, pp. 343-362, 2007.

[6] E. B. Gaskin, J. D. Harless, J. S. Wefel et al., "Fluorescence changes in remineralized and nonremineralized enamel adjacent to glass ionomer art restorations: an in vitro study," Journal of Dentistry for Children, vol. 74, no. 3, pp. 215-220, 2007.

[7] Y. Yoshida, B. van Meerbeek, Y. Nakayama et al., "Evidence of chemical bonding at biomaterial-hard tissue interfaces," Journal of Dental Research, vol. 79, no. 2, pp. 709-714, 2000.

[8] B. Van Meerbeek, S. Inokoshi, M. Braem, P. Lambrechts, and G. Vanherle, "Morphological aspects of the resin-dentin interdiffusion zone with different dentin adhesive systems," Journal of Dental Research, vol. 71, no. 8, pp. 1530-1540, 1992.

[9] D. F. Cefaly, F. P. Valarelli, B. G. Seabra, R. F. Mondelli, and M. F. Navarro, "Effect of time on the diametral tensile strength of resin-modified restorative glass ionomer cements and compomer," Brazilian Dental Journal, vol. 12, no. 3, pp. 201204, 2001.

[10] J. D. Scholtanus and M.-C. D. N. J. M. Huysmans, "Clinical failure of class-II restorations of a highly viscous glass-ionomer material over a 6-year period: a retrospective study," Journal of Dentistry, vol. 35, no. 2, pp. 156-162, 2007.

[11] R. Hickel, C. Kaaden, E. Paschos, V. Buerkle, F. García-Godoy, and J. Manhart, "Longevity of occlusally-stressed restorations in posterior primary teeth," American Journal of Dentistry, vol. 18, no. 3, pp. 198-211, 2005.

[12] C. R. Brito, L. G. Velasco, G. A. V. C. Bonini, J. C. P. Imparato, and D. P. Raggio, "Glass ionomer cement hardness after different materials for surface protection," Journal of Biomedical Materials Research-Part A, vol. 93, no. 1, pp. 243-246, 2010.

[13] T. J. Algera, C. J. Kleverlaan, A. J. De Gee, B. Prahl-Andersen, and A. J. Feilzer, "The influence of accelerating the setting rate by ultrasound or heat on the bond strength of glass ionomers used as orthodontic bracket cements," European Journal of Orthodontics, vol. 27, no. 5, pp. 472-476, 2005.

[14] R. N. B. van Duinen, C. J. Kleverlaan, A. J. de Gee, A. Werner, and A. J. Feilzer, "Early and long-term wear of 'Fast-set' conventional glass-ionomer cements," Dental Materials, vol. 21, no. 8, pp. 716-720, 2005.

[15] R. N. B. Van Duinen, C. L. Davidson, A. J. de Gee, and A. J. Feilzer, "In situ transformation of glass-ionomer into an enamel-like material," The American Journal of Dentistry, vol. 17, no. 4, pp. 223-227, 2004.

[16] GCP Dental, 2011, http://www.gcp-dental.com/wp-content/ uploads/2012/08/Instructions-of-use-glass-fill-UK.pdf.

[17] K. Gorseta, D. Glavina, A. Borzabadi-Farahani et al., "Oneyear clinical evaluation of a Glass Carbomer fissure sealant, a preliminary study," European Journal of Prosthodontics and Restorative Dentistry, vol. 22, no. 2, pp. 67-71, 2014.

[18] A. S. Goldman, X. Chen, M. Fan, and J. E. Frencken, "Methods and preliminary findings of a cost-effectiveness study of glassionomer-based and composite resin sealant materials after $2 \mathrm{yr}$,"
European Journal of Oral Sciences, vol. 122, no. 3, pp. 230-237, 2014.

[19] X. Chen, M. Q. Du, M. W. Fan, J. Mulder, M. C. D. N. J. M. Huysmans, and J. E. Frencken, "Caries-preventive effect of sealants produced with altered glass-ionomer materials, after 2 years," Dental Materials, vol. 28, no. 5, pp. 554-560, 2012.

[20] X. Chen, M. Du, M. Fan, J. Mulder, M.-C. Huysmans, and J. E. Frencken, "Effectiveness of two new types of sealants: retention after 2 years," Clinical Oral Investigations, vol. 16, no. 5, pp. 14431450, 2012.

[21] T. L. Lenzi, T. K. Tedesco, A. F. Calvo, H. A. Ricci, J. Hebling, and D. P. Raggio, "Does the method of caries induction influence the bond strength to dentin of primary teeth?" The Journal of Adhesive Dentistry, vol. 16, no. 4, pp. 333-338, 2014.

[22] D. P. Raggio, D. Hesse, T. L. Lenzi, C. Guglielmi, and M. M. Braga, "Is Atraumatic restorative treatment an option for restoring occlusoproximal caries lesions in primary teeth? A systematic review and meta-analysis," International Journal of Paediatric Dentistry, vol. 23, no. 6, pp. 435-443, 2013.

[23] S. Mickenautsch, V. Yengopal, and A. Banerjee, "Atraumatic restorative treatment versus amalgam restoration longevity: a systematic review," Clinical Oral Investigations, vol. 14, no. 3, pp. 233-240, 2010.

[24] S. B. Cehreli, R. E. Tirali, Z. Yalcinkaya, and Z. C. Cehreli, "Microleakage of newly developed glass carbomer cement in primary teeth," European Journal of Dentistry, vol. 7, no. 1, pp. 15-21, 2013.

[25] N. Zainuddin, N. Karpukhina, R. V. Law, and R. G. Hill, "Characterisation of a remineralising Glass Carbomer ionomer cement by MAS-NMR Spectroscopy," Dental Materials, vol. 28, no. 10, pp. 1051-1058, 2012.

[26] T. K. Tedesco, C. C. Bonifácio, D. Hesse, C. J. Kleverlaan, T. L. Lenzi, and D. P. Raggio, "Bonding longevity of flowable GIC layer in artificially carious dentin," International Journal of Adhesion and Adhesives, vol. 51, pp. 62-66, 2014.

[27] M. Giannini, R. M. Carvalho, L. R. M. Martins, C. T. S. Dias, and D. H. Pashley, "The influence of tubule density and area of solid dentin on bond strength of two adhesive systems to dentin," Journal of Adhesive Dentistry, vol. 3, no. 4, pp. 315-324, 2001.

[28] M. Nakajima, H. Sano, I. Urabe, J. Tagami, and D. H. Pashley, "Bond strengths of single-bottle dentin adhesives to cariesaffected dentin," Operative Dentistry, vol. 25, no. 1, pp. 2-10, 2000 . 

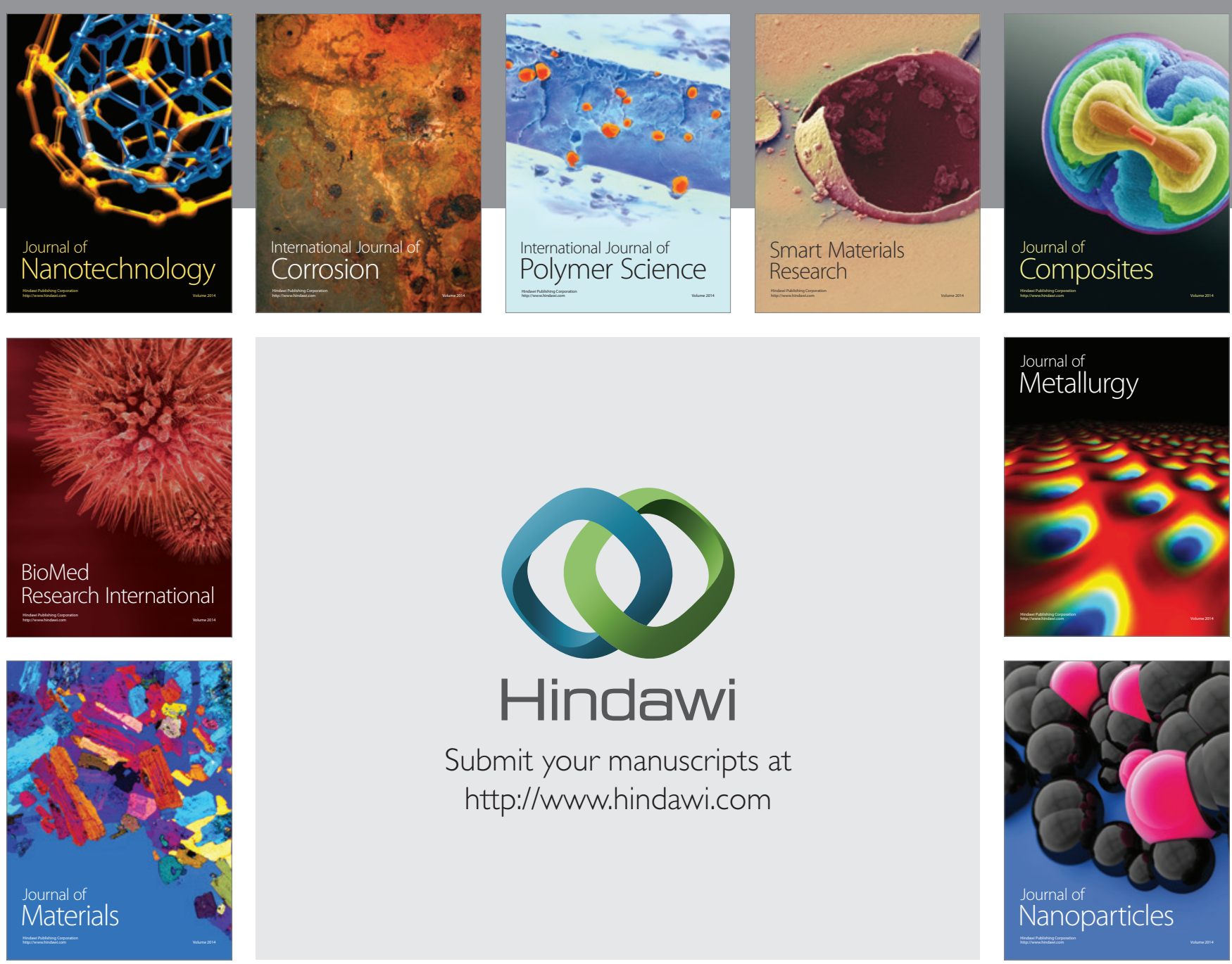

Submit your manuscripts at http://www.hindawi.com
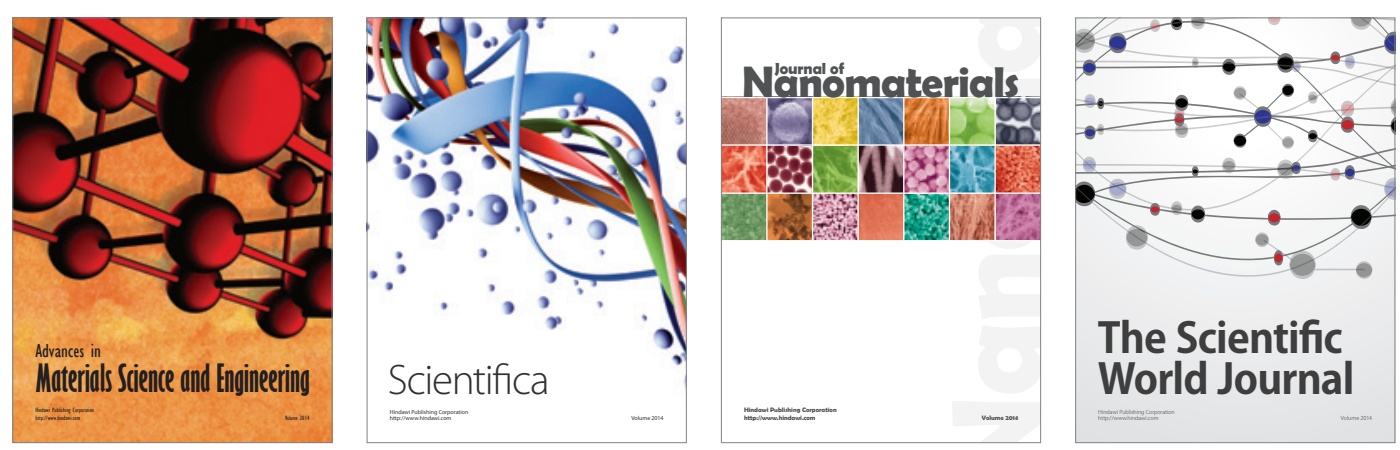

\section{The Scientific World Journal}
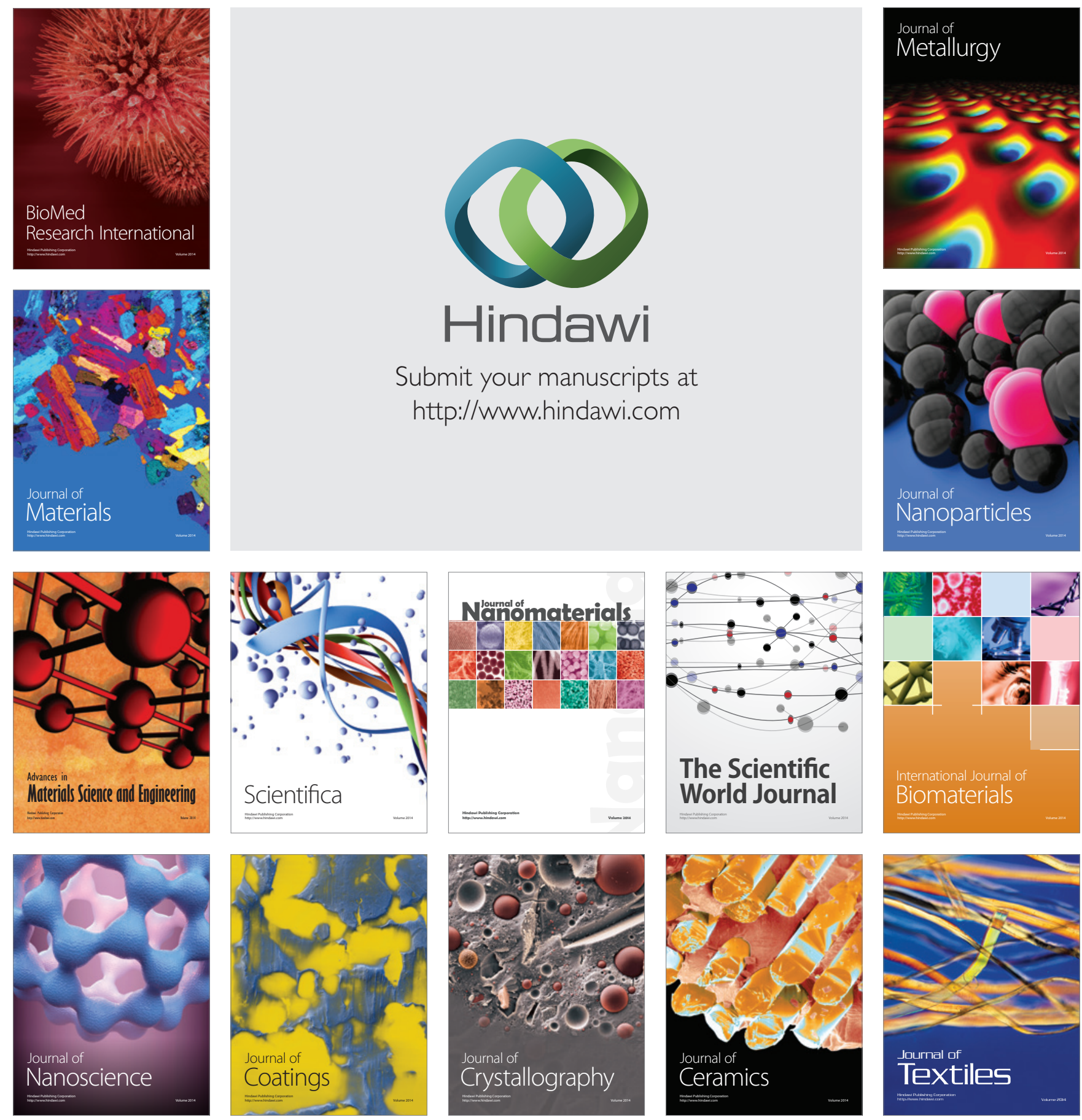